
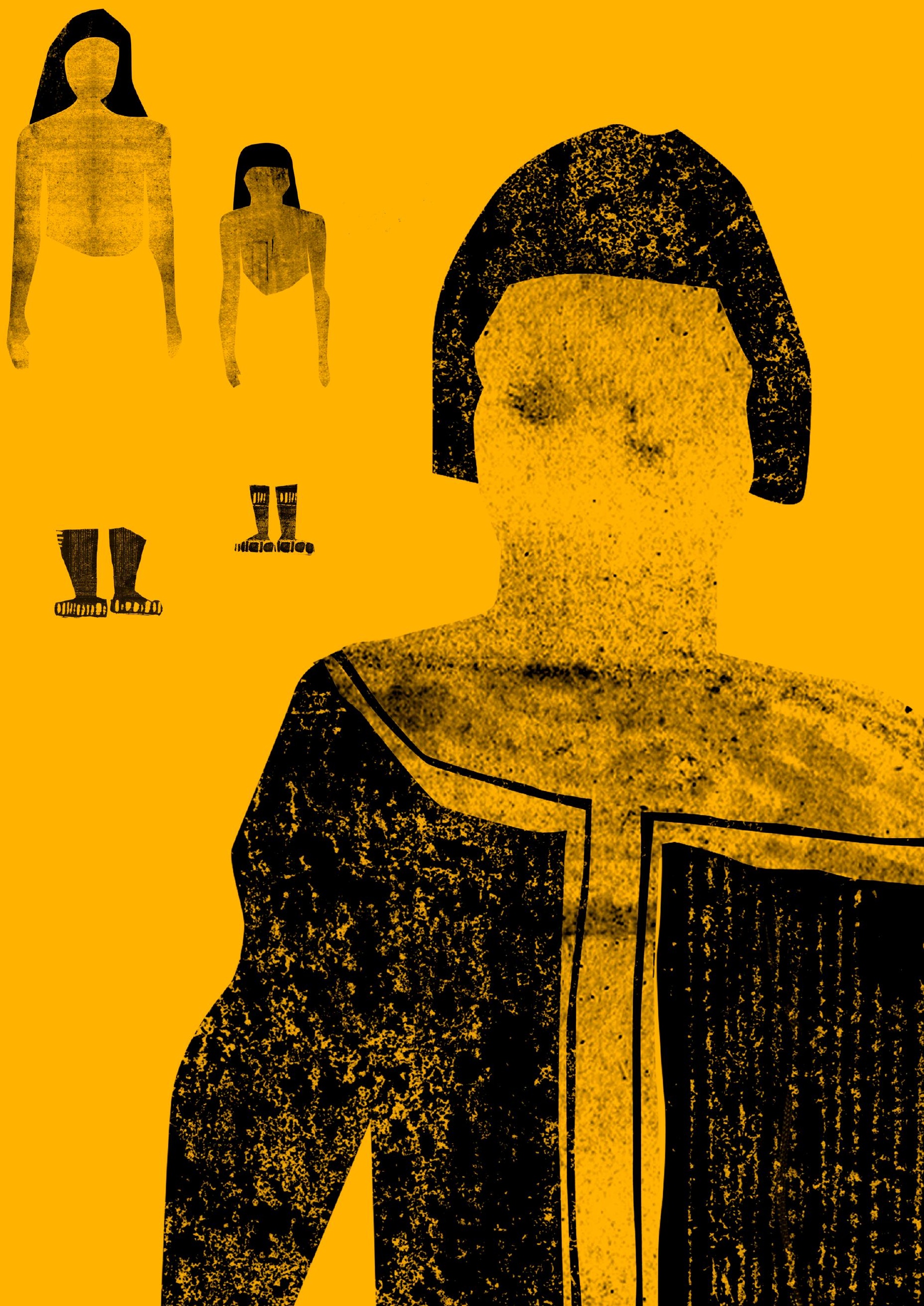


\section{Contribuições ao estudo da terminologia de parentesco Kraho e}

\section{Timbira $^{1}$}

Carlos Paulino ${ }^{2}$

\section{Resumo}

A terminologia de parentesco Kraho foi primeiro descrita por Julio Melatti e tem entre suas características fundamentais a obliquidade e o princípio de unidade do grupo de irmãos do mesmo sexo. Este texto tem por objetivo revisitar a clássica descrição de Melatti sob a luz de novos dados obtidos entre os Kraho, bem como de dados de outros povos Timbira - com destaque para a contribuição de Maria Elisa Ladeira sobre os regimes de troca matrimonial e onomástica entre os Kraho e Canela, e para a terminologia Apinajé descrita por Roberto DaMatta. A partir dos dados, proponho que é possível pensar um sistema terminológico comum aos povos Timbira. Dentre outras coisas, o artigo procura vislumbrar como a terminologia de parentesco se integra com as trocas matrimoniais e onomásticas, mesmo entre povos que, como os Timbira, não possuem regra positiva de casamento.

Palavras-chave: Timbira; Kraho; Parentesco; Terminologia; Troca.

\begin{abstract}
The Kraho kinship terminology was first described by Julio Melatti and counts among its key features skewing and the principle of unity of the same sex sibling group. This text aims to revisit Melatti's classic description in the light of new data obtained among the Kraho, as well as data from other Timbira groups - with special emphasis on the contribution of Maria Elisa Ladeira on Kraho and Canela matrimonial and onomastic exchange regimes, and on the Apinajé terminology as described by Roberto DaMatta. Based on the data, I propose it is possible to imagine a single terminological system common to all Timbira groups. The article tries to discern how kinship terminology integrates with matrimonial and onomastic exchange regimes even among groups such as the Timbira which have no positive marriage rule.
\end{abstract}

Keywords: Timbira; Kraho; Kinship; Terminology; Exchange.

\footnotetext{
1 Agradeço a Marcio Silva, Ian Packer e aos pareceristas da revista Maloca pela leitura e comentários que me permitiram chegar à versão final deste artigo.

2 Doutorando em Antropologia Social pela Universidade Federal de São Carlos. E-mail: carlosmopaulino@ gmail.com.
} 
A compreensão do modo de operação das terminologias de parentesco é um dos problemas fundamentais com o qual, mais cedo ou mais tarde, todos os etnólogos se deparam em campo; portanto não é de surpreender que a descrição dessas terminologias seja uma das práticas mais antigas da antropologia. A descrição que faço aqui da terminologia de parentesco Timbira, a partir sobretudo do caso Kraho, busca revisitar outras descrições de terminologias desses povos e, a partir desses dados, consolidar um modelo geral que já se entrevia nesses trabalhos. Além de minha própria pesquisa de campo, utilizo três fontes fundamentais para embasar o modelo proposto; são os trabalhos de Melatti (1973), DaMatta (1976) e Ladeira (1982). Em especial, a forma como apresento os termos de parentesco, listando-os e descrevendo-os com o auxílio de diagramas de filiação e casamento, é tomada de empréstimo de Melatti, embora os diagramas e a descrição tenham pequenas diferenças.

Contudo, antes de prosseguir, quero ressaltar um ponto sobre a tarefa que este texto se propõe. A descrição de uma terminologia de parentesco não é uma reprodução total e exata de todos os termos e suas aplicações em determinado contexto, nem tampouco uma regra imutável que é seguida à risca por todas as pessoas que compartilham desse repertório. Antes, penso que uma terminologia de parentesco deve ser entendida como um saber que descreve, classifica e produz relações entre pessoas, fornecendo uma base para o ordenamento e a atribuição de sentidos e valores a essas relações. A descrição que fazemos desse saber pode ser encarada como um conjunto de regras gerais para aplicação desses termos, regras que podem ser postas em prática de maneiras diferentes conforme cada caso.

Podemos pensar a descrição da terminologia de parentesco Timbira como um modelo que, como todo modelo, simplifica o objeto descrito para que possamos estudar algumas de suas propriedades (SILVA, 2017). No caso, estão ausentes do modelo que apresento os detalhes do sistema de atitudes relacionado à cada um dos termos e relações descritos, bem como as possibilidades de construção e transformação das relações de parentesco por diferentes meios. Isso não significa que o emprego da terminologia não esteja relacionado a processos particulares de construção de relações e com as atitudes assumidas pelas pessoas nessas relações; muito pelo contrário, a mudança no termo aplicado a uma pessoa é, via de regra, acompanhada pela construção de uma nova relação que implica uma mudança na atitude para com essa pessoa. Falar sobre as relações e classificá-las - através da terminologia - também produz essas mesmas relações; a terminologia tem efeitos bem reais. Poderíamos dizer que, assim como a partilha de substância e o convívio são formas de produzir, atualizar e transformar relações de parentesco (COELHO DE SOUZA, 2004), o emprego da terminologia também é um aspecto fundamental e eficaz da produção e/ou transformação dessas relações. Embora na prática as relações muitas vezes existam em situações não previstas pelo modelo, ou não sejam condizentes com a expectativa colocada pelo modelo, isso não significa que tal expectativa não exista nem que ela não seja relevante (ainda que como contraponto) para a construção empírica das relações (SAHLINS, 2013). 
Abstraindo-se esses aspectos processuais das relações de parentesco, as terminologias são tradicionalmente descritas a partir de relações fundamentais, tais como filiação e casamento. $\mathrm{O}$ pressuposto aqui é o de que - mesmo que esses tipos de relações não sejam definidas no modo de pensar Timbira da mesma forma como os definimos em nosso modo de pensar - há, entre os Timbira, relações que, não sendo ontologicamente equivalentes a essas relações, ainda assim podem ser comparadas com elas. Em outras palavras, mesmo que os Timbira não definam "filiação" e "casamento" da mesma forma que um não indígena faria, ainda assim é possível comparar as diferentes relações agrupadas sob esses rótulos. O objetivo aqui não é reduzir as relações Timbira a um espelho das nossas, mas sim, pelo contrário, ressaltar as diferenças apesar das semelhanças. Parafraseando Viveiros de Castro (2002), é justamente esse o propósito de juntar relações diferentes sob uma mesma palavra: fazer "filiação" e "casamento" quererem dizer outra coisa.

Os Kraho possuem uma complexa terminologia de parentesco que utilizam para classificar e se referir às pessoas com as quais se relacionam. Melatti $(1970,1973)$ foi o primeiro autor a descrever essa terminologia, elencando quais as posições genealógicas abarcadas por cada termo e quais as regras e expectativas de comportamento entre os diferentes tipos de parentes. A partir da obliquidade característica dessa terminologia e do conjunto de posições genealógicas coberto por alguns termos, Melatti classifica inicialmente o sistema terminológico Kraho como sendo do tipo Crow segundo a tipologia estabelecida por Murdock (1949). Porém, Melatti (1973) e, com mais ênfase, Ladeira (1982) notam também que os sistemas terminológicos Timbira possuem não somente equações Crow, mas também Omaha ${ }^{3}$, associadas à transmissão de nomes, gerando através delas mais de uma possibilidade classificatória para os primos cruzados. Além disso, DaMatta (1976) e Ladeira (1982) apontam que todos os povos jê do norte possuem um mesmo repertório de termos (com variações dialetais) e que há um conjunto de posições genealógicas para as quais tais termos podem ser usados que é comum a todos esses povos. Esse conjunto de posições consiste nos parentes paralelos de qualquer geração e cruzados da geração imediatamente acima de ego $\left(\mathrm{G}^{+1}\right)$.

Pode-se observar na figura I que em $\mathrm{G}^{+1}$ os parentes cruzados de ambos os lados (patri e matrilateral) são terminologicamente elevados à geração dos avós $\left(\mathrm{G}^{+2}\right)$. Se tomarmos como base a descrição formal desses tipos de terminologias feita por Lounsbury (1964), veremos que em nenhuma das variações descritas por esse autor os parentes cruzados patri e matrilaterais em $\mathrm{G}^{+1}$ são terminologicamente alçados a $\mathrm{G}^{+2}$, como ocorre entre os Timbira. Da mesma forma, em nenhuma das variações os filhos de irmãos(ãs) de sexo oposto (parentes cruzados em $\mathrm{G}^{-1}$ ) são todos terminologicamente rebaixados a $\mathrm{G}^{-2}$ seja para ego masculino ou feminino. Em qualquer

3 Os sistemas terminológicos Crow e Omaha são frequentemente estudados em conjunto por serem como "imagens espelhadas" um do outro. Sua característica distintiva é a obliquidade, ou em outras palavras, a distribuição não geracional de alguns termos. 


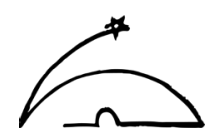

uma das fórmulas descritas por Lounsbury, o que ocorre é sempre que os parentes cruzados de um dos lados (patri ou matrilateral) são elevados enquanto os do outro são rebaixados. Logo, o que se têm entre os Timbira (e, possivelmente, entre todos os jê do norte que compartilham desse repertório de termos de parentesco) é uma conjunção entre os padrões Crow e Omaha, um sistema terminológico que realmente merece a alcunha mais abrangente de "Crow-Omaha".

Assim, embora a breve descrição a seguir se baseie nos termos usados pelos Kraho, podemos adiantar que a mesma estrutura de aplicação dos termos é válida para os demais povos Timbira (e jê do norte).
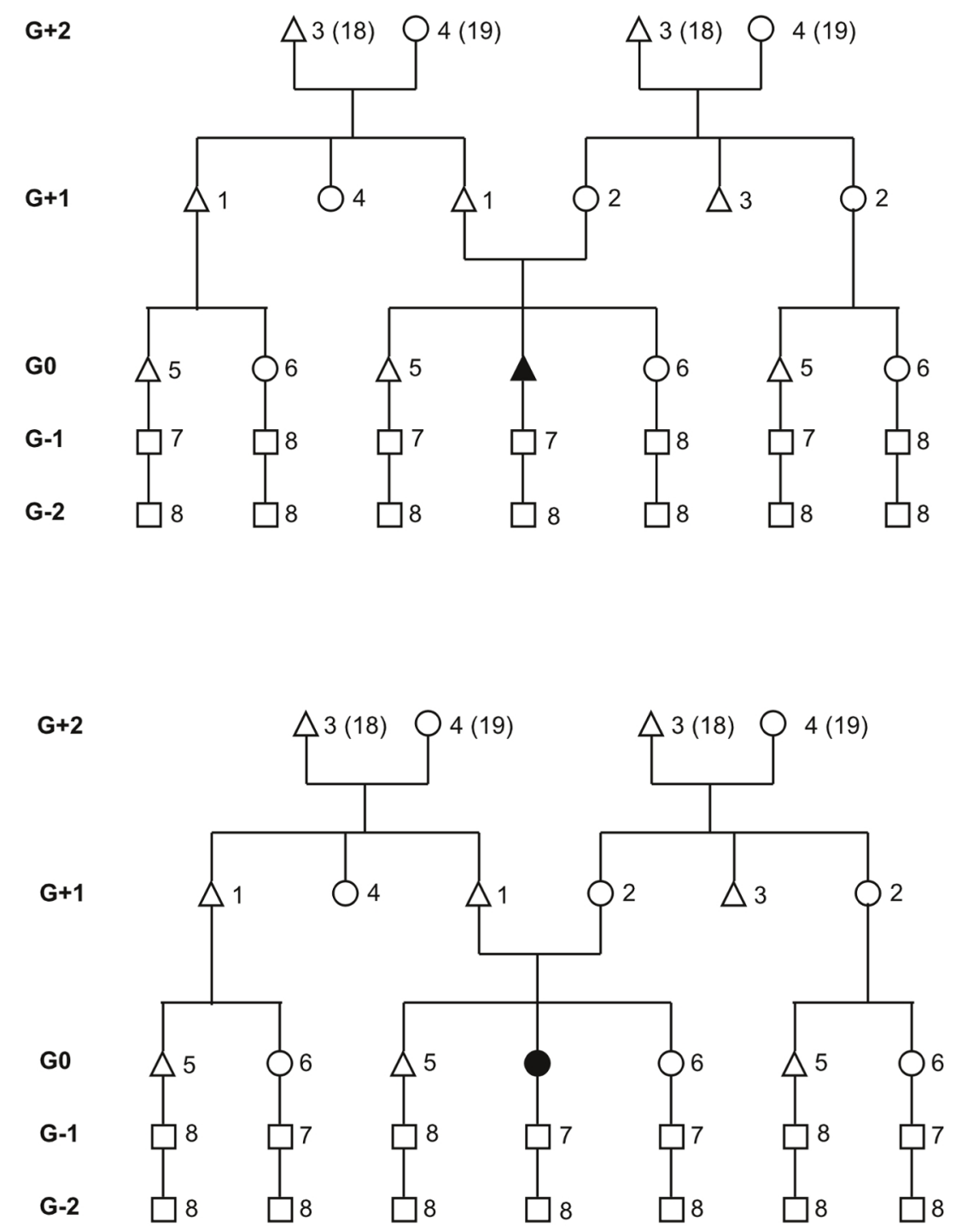

Figura I. Repertório de termos comum aos povos "jê do norte".

Entre parênteses as variações Kraho para $\mathrm{G}^{+2}$. Fontes: PAULINO, 2016; MELATTI 1973.

1) I-nxũ - termo usado por ego masculino ou feminino para se referir ao(s) pai(s) e todos os homens que um pai chame de itõ (5). Ex.: F, FB, FFBS etc. 
2) I-nxe - termo usado por ego masculino ou feminino para se referir à(s) mãe(s) e todas as mulheres que uma mãe chame de itoĩ (6). Ex.: M, MZ, MMZD etc.

3) Keti - termo usado por ego masculino ou feminino para se referir a todos os homens que uma mãe chame de itõ (5), bem como a todos os seus parentes de sexo masculino que tenham duas ou mais gerações de diferença para consigo. Também é usado por ego masculino para se referir a qualquer homem que tenha o mesmo nome que si e seja mais velho do que ego. Ex.: MB, MMZS, MF, FF, MFF, FMF etc.

4) $T y j$ - termo usado por ego masculino e feminino para se referir a todas as mulheres que um pai chame de itoi (6), bem como a todas as suas parentes de sexo feminino que tenham duas ou mais gerações de diferença para consigo. Também é usado por ego feminino para se referir a qualquer mulher que tenha o mesmo nome que si e seja mais velha do que ego. Ex.: FZ, FFBD, FM, MM, FFM, MMM etc.

5) I-tõ - termo usado por ego masculino ou feminino para se referir a todos os homens que sejam filhos de um homem a quem chamam de inxũ (1) e/ou de uma mulher a quem chamam de inxe (2). Ex.: B, FBS, MZS, FFBSS, MMZDS etc.

6) I-toĩ - termo usado por ego masculino ou feminino para se referir a todas as mulheres que sejam filhas de um homem a quem chamam de inxũ (1) e/ou de uma mulher a quem chamam de inxe (2). Ex.: Z, MZD, FBD, MMZDD, FFBSD etc.

7) $I-k r a$ - termo usado por ego masculino ou feminino para se referir aos filhos(as) de ambos os sexos, bem como aos filhos(as) de todos os homens chamados de itõ (5) (para ego masculino) ou aos filhos(as) de todas as mulheres chamadas de itoĩ (6) (para ego feminino). Ex.: $\mathrm{S}, \mathrm{D}, \mathrm{mBS}, \mathrm{mBD}, \mathrm{fZS}$, fZD etc.

8) I-tamxwy - termo usado por ego masculino ou feminino para se referir aos filhos(as) de ambos os sexos de todas as pessoas a quem chamam ikra (7) ou itamxwy (8), bem como aos filhos(as) de todos os homens chamados de itõ (5) (para ego feminino) ou aos filhos(as) de todas as mulheres chamadas de itoĩ (6) (para ego masculino). Ex.: SS, SD, DD, DS, fBS, fBD, mZS, mZD, SSS, DDD etc.

As descrições para cada termo não são exaustivas; há outras formas de aplicar alguns desses termos aos primos cruzados e seus descendentes, que serão explicadas mais adiante. Essa descrição dá conta apenas das relações em um núcleo mais próximo de ego para o qual a aplicação dos termos, salvo exceções, tende a ser invariante. Há, no entanto, dois outros termos com os quais me deparei durante minha pesquisa de campo sobre os quais não encontrei nenhuma menção anterior em fontes bibliográficas. São eles:

18) Vei inx $\tilde{u}$ - termo usado por ego masculino ou feminino para se referir ao(s) pai(s) (de sexo masculino) de um pai, de uma mãe, de um vei inxũ (18) ou de uma vei (19). Ex.: FF, MF, MFF, FMF etc.

19) $V e i$ - termo usado por ego masculino ou feminino para se referir à(s) mãe(s) de um pai, de uma mãe, de um vei inxũ (18) ou de uma vei (19). Ex.: FM, MM, FFM, MMM etc. 
Penso que é bastante plausível a hipótese de que - devido à semelhança fonética com a palavra de língua portuguesa "velho/a", bem como à semelhança estrutural com a categoria de avô(ó) - se tratem de neologismos na língua Kraho apropriados da língua portuguesa. Nas descrições de Melatti (1970, 1973), DaMatta (1976) e, ao que me parece, em toda a bibliografia sobre parentesco de grupos jê do norte as posições designadas por esses termos são respectivamente cobertas pelos termos keti (3) e tyj (4), ambos descritos anteriormente. Portanto, não posso afirmar que esses termos (ou variações deles) existam entre qualquer outro povo Timbira além dos Kraho.

De fato, há mais sinais de que a inclusão dos termos vei (19) e vei inxũ (18) no vocabulário Kraho seja recente, pois o termo recíproco a eles é itamxwy (8), mesmo termo que é utilizado como forma recíproca dos termos keti (3) e tyj (4). Para além, a transmissão de nomes - sempre descrita como sendo feita de keti (3) para ego masculino e de tyj (4) para ego feminino - também pode ser feita pelos vei inxũ (18) e vei (19). Embora eu tenha encontrado em minha pesquisa apenas uma pessoa que reconheceu a possibilidade de chamar essas pessoas pelos termos keti (3) e tyj (4), tudo indica que em algum nível essas categorias (vei inxũ [18] / keti [3], vei [19] / tyj [4]) ainda são equivalentes, a distinção entre elas apontando meramente para a diferença geracional (vei [19] e vei inxũ [18] de $\mathrm{G}^{+2}$ para cima, keti [3] e tyj [4] abaixo disso). Sendo assim, considero os termos vei (19) e vei inxũ (18) como subcategorias englobadas pelos termos keti (3) e tyj (4). Em alguns casos empíricos, os termos vei (19) e vei inxũ (18) parecem funcionar também como formas de tecnonímia, pois existe a possibilidade de que pessoas classificadas por ego como ikra (7), ixwyjê (16) ou ipẽajê (17) (termos descritos a seguir) passem a chamar ego dessa forma após terem seu primeiro filho(a), ou seja, a partir do momento em que ego se torna um vei (19) ou vei inxũ (18) de um filho(a) seu.

Para além dos termos já descritos, a terminologia de parentesco Timbira dispõe de um outro subconjunto de termos usados para se referir aos afins, aquelas pessoas relacionadas umas às outras através de uma relação de casamento. Um aspecto fundamental do sistema de parentesco Kraho (e Timbira) que precisa ser lembrado é o princípio da unidade do grupo de irmãos de mesmo sexo, segundo o qual homens que se tratem mutuamente pelo termo itõ (5) ou mulheres que se tratem mutuamente pelo termo itoi (6) aplicam o mesmo termo de parentesco a uma pessoa qualquer, assim como essa outra pessoa qualquer aplica o mesmo termo de parentesco a eles(as) (MELATTI, 1973). Esse princípio é evidente não só nos termos já descritos (como nas equações $\mathrm{F}=\mathrm{FB}=\mathrm{FFBS}=\mathrm{FMZS}$ e $\mathrm{M}=\mathrm{MZ}=\mathrm{MMZD}=\mathrm{MFBD}$ para os termos 1 e 2), como também na terminologia para os afins, nas equações $\mathrm{W}=\mathrm{BW}=\mathrm{WZ}$ e $\mathrm{H}=\mathrm{ZH}=\mathrm{HB}$. Assim, um homem não possui "cunhadas", mas apenas "esposas", e uma mulher não possui "cunhados", somente "esposos" (LADEIRA, 1982). A descrição de DaMatta dos termos de afinidade Apinajé difere um pouco nesse ponto ao elencar termos específicos para fZH e mBW (DAMATTA, 1976), porém o termo

$4 \quad$ DaMatta (1976) menciona, entretanto, que alguns Apinajé traduzem o termo equivalente a keti (3) por "vovô" e utilizam esse vocábulo. 
para $\mathrm{fZH}$ parece ser uma variação do termo para $\mathrm{H}$ com um aumentativo $(t i)$.

Sobre os termos para afins é interessante notar que a terminologia Timbira diferencia mWB (11) de mZH (17) e fHZ (12) de fBW (16), gerando assim diferenciações internas à categoria que em português chamamos de "cunhado(a)". É notável também o fato de que a obliquidade (que veremos se manifestar com relação aos primos cruzados e seus descendentes mais adiante através das equações de tipo Crow-Omaha), também aparece aqui nos termos para afins, como se vê no emprego dos termos hoxwỳjê (15), ixwỳjê (16) ipẽajê (17) em mais de uma geração.

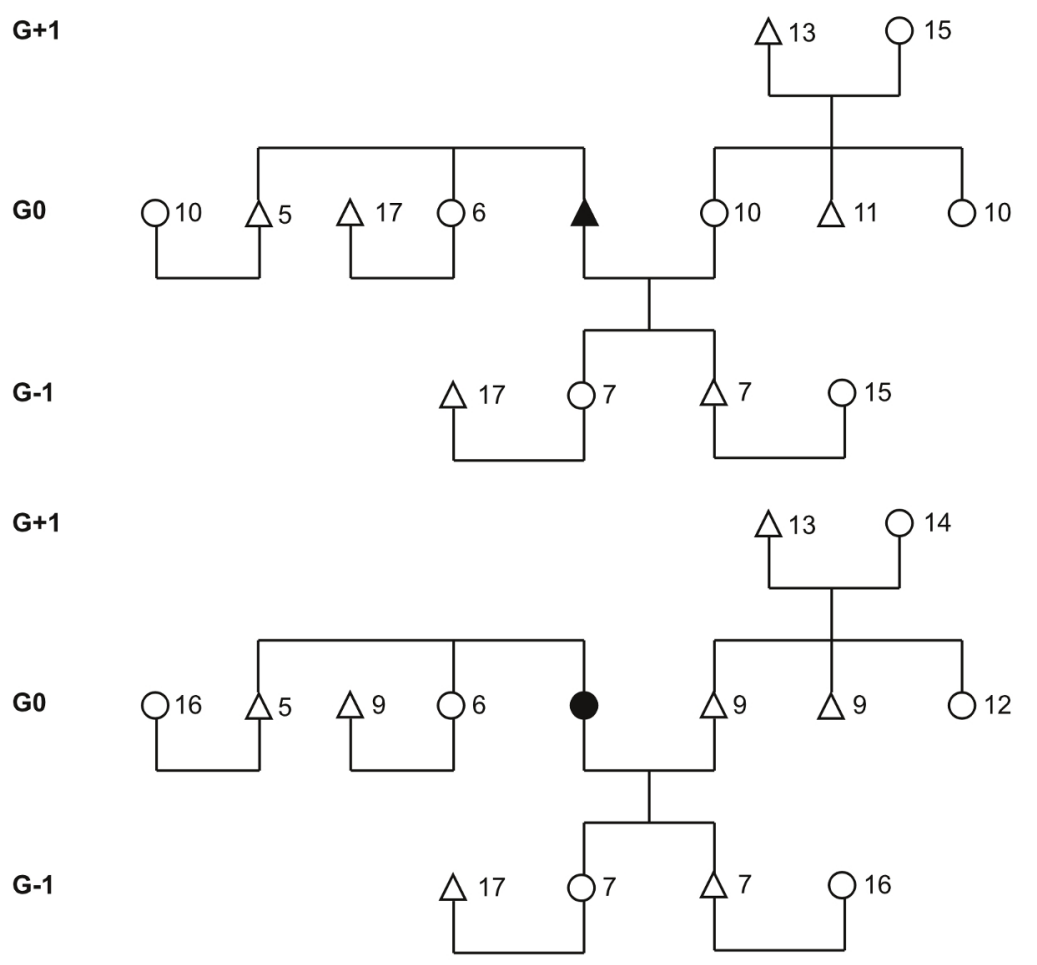

Figura II. A distribuição dos termos de afinidade para ego masculino e feminino. Fonte: PAULINO, 2016; MELATTI 1973; LADEIRA 1982.

9) I-pjẽ - usado por ego feminino para se referir ao(s) seu(s) cônjuge(s), todos os homens que um cônjuge chame de itõ (5) e todos os cônjuges das mulheres a quem chame de itoĩ (6). Ex.: $\mathrm{fH}, \mathrm{fHB}, \mathrm{fHFBS}, \mathrm{fZH}, \mathrm{fMZDH}$, etc.

10) I-prõ - usado por ego masculino para se referir à(s) sua(s) cônjuge(s), todas as mulheres que uma cônjuge chame de itoĩ (6) e todas as cônjuges dos homens a quem chame de itõ (5). Ex.: mW, mWZ, mWMZD, mBW, mFBSW, etc.

11) I-pãjê - usado por ego masculino para se referir a todos os homens que sua(s) cônjuge(s) chamem de itõ (5). Ex.: mWB, mWMZS, mWFBS etc.

12) I-tyctyjê - usado por ego feminino para se referir a todas as mulheres que seu(s) cônjuge(s) chamem de itoi (6). Ex.: fHZ, fHMZD, fHFBD etc.

13) I-krãtumjê - usado por ego masculino ou feminino para se referir a todos os homens que seu(s) cônjuge(s) chamem de inxũ (1). Ex.: HF, WF, HFB, WFB etc. 
14) Prôpekêj - usado por ego feminino para se referir a todas as mulheres que seu(s) cônjuge(s) chamem de inxe (2). Ex.: fHM, fHMZ etc.

15) Hoxwỳjê - usado por ego masculino para todas as mulheres que sua(s) cônjuge(s) chamem de inxe (2), bem como para a(s) cônjuge(s) de todos os homens a quem chame de ikra (7). Ex.: mWM, mWMZ, mSW, mBSW etc.

16) $I$-xwỳje - usado por ego feminino para todas as mulheres que sejam cônjuge de algum homem que chamem de itõ (5) ou de ikra (7). Ex.: fBW, fFBSW, fMZSW, fSW, fZSW etc.

17) I-pẽaje - usado por ego masculino para se referir a todos os homens que sejam cônjuge de alguma mulher que chamem de itoi (6). Usado também por ego masculino ou feminino para se referir a todos os homens que sejam cônjuge de alguma mulher que chamem de ikra (7). Ex.: $\mathrm{mZH}, \mathrm{mFBDH}, \mathrm{mMZDH}, \mathrm{DH}, \mathrm{mBDH}, \mathrm{fZDH}$ etc.

Algumas observações devem ser feitas sobre a descrição até aqui. Como Melatti nos lembra, os termos de parentesco Timbira possuem diversos sinônimos, que podem inclusive abranger escopos um pouco diferentes, como o termo ipre que abrange os termos ipãjê (11) e ityctyjê (12), o termo icjêjê que abrange os termos itõ (5) e itoĩ (6), ou os termos ijapar e ijaparxwôj que abrangem respectivamente apenas homens ou mulheres classificados dentro do termo itamxwy (8). Outro exemplo são os termos específicos para se referir a parentes falecidos, entre os quais há termos que não possuem correlato direto na terminologia para os parentes vivos, o que permite uma outra análise da terminologia (MELATTI, 1973).

Os termos aqui apresentados são de referência (utilizados por ego para se referir a uma terceira pessoa com um interlocutor). Na maior parte dos casos, a terminologia vocativa é a mesma, mas - para com algumas categorias de parentes mais do que para com outras - parece haver a liberdade de utilizar os nomes pessoais de forma vocativa invés de um termo específico da relação; é o caso do par ipjẽ (9) / iprõ (10), em que o uso dos nomes pessoais denota a não existência de relação de consubstancialidade e, portanto, a liberdade sexual.

Por vezes, os termos recebem sufixos ou são acompanhados de outras palavras na língua Kraho para indicar idade relativa da pessoa referida. Assim os termos keti (3) e tyj (4) podem se transformar nas formas ketre e tyre respectivamente para indicar pessoas mais novas ou de geração igual ou inferior a ego; outros termos poderiam vir seguidos da palavra prêc que indica alguém mais velho ou cupry que também indica alguém mais novo.

A partícula $i$ - que aparece no começo da maioria dos termos de parentesco poderia ser traduzida como o pronome possessivo "meu" e pode ser substituída por outras como $a$-para indicar "seu" ou pa- para indicar "nosso", resultando em formas como patõ (5) ou anxe (2) por exemplo. Os termos que não começam com essa partícula também possuem certas variações similares, mas não sou capaz de descrevê-las de forma consistente.

Além das posições de parentesco já descritas acima, há outras formas de aplicar cada um dos termos de parentesco Kraho a outras pessoas que não as indicadas na descrição de cada termo, ou também de reclassificar pessoas com quem se tem uma relação genealógica. Uma dessas formas 
é através da identificação de pares de termos associados a casais, como o par inxũ (1) / inxe (2), vei inxũ (18) / vei (19) ou ainda, conforme DaMatta (1976), keti (3) / tyj (4). Assim, por exemplo, uma pessoa pode ser chamada por um ego qualquer de inxũ (1) após se casar com uma inxe (2) de ego, ainda que antes desse casamento não pudesse ser enquadrado nessa categoria.

Outra forma de aplicar termos de parentesco é através da identificação entre pessoas de mesmo nome. Quando duas pessoas possuem o mesmo nome, podem, quando quiserem, aplicar a qualquer outra pessoa o termo que seria aplicado a ela por seu(a) homônimo(a), assim como qualquer pessoa pode aplicar a alguém homônimo(a) de qualquer parente o mesmo termo que aplica a esse parente. Essa regra da homonímia é utilizada não somente para reclassificar relações, como também para incorporar pessoas de fora em uma dada rede de relações. Essa forma de incorporação - muito comum, por exemplo, na recepção de não indígenas numa aldeia - se dá através da transmissão de um nome ao forasteiro por parte de qualquer pessoa que se interesse em fazê-lo, independentemente das regras tradicionais de transmissão de nomes, de tal modo que o recém-chegado passa a integrar a rede de relações a partir de sua identificação com a pessoa que lhe transmitiu nome.

Existem ainda outros termos utilizados pelos Kraho (com termos cognatos para os outros Timbira) para se referir a certas pessoas que não podem ser descritos em função de relações de filiação e matrimônio, como feito até agora. São eles:

20) I-pantu - usado por ego masculino ou feminino para se referir a qualquer pessoa a quem tenha transmitido seus nomes, ou que seja seu(a) homônimo(a) e mais jovem.

21) I-khwynõ - usado por ego masculino ou feminino para se referir a qualquer pessoa que tenha nascido no mesmo dia que si; ou por ego masculino para se referir a qualquer homem que tenha sido "prefeito" ou líder em algum rito de iniciação junto consigo; ou ainda por ego feminino para se referir a qualquer mulher que tenha sido associada a uma metade ou grupo de rapazes em algum rito de iniciação junto consigo (MELATTI, 1973).

22) Hõpin - usado por ego masculino ou feminino para se referir a qualquer homem cujo conjunto de nomes seja ligado ao conjunto de nomes de ego pela relação de amizade formal.

23) Pinxwôj - usado por ego masculino ou feminino para se referir a qualquer mulher cujo conjunto de nomes seja ligado ao conjunto de nomes de ego pela relação de amizade formal.

Uma pessoa qualquer só pode transmitir seus nomes - e, portanto, passar a chamar de ipantu (20) - para alguém a quem classifique inicialmente como itamxwy (8). O termo recíproco que deve ser utilizado em ambos os casos é o mesmo: keti (3) no caso de alter masculino e tyj (4) no caso de alter feminino.

Os termos ikhwynõ (21), hõpin (22) e pinxwôj (23) denotam relações bastante peculiares - geralmente chamadas em português de companheirismo e amizade formal -, descritas por Carneiro da Cunha ([1979]1986) e Azanha (1984), sobre as quais não tratarei nesta oportunidade. Cito-os apenas para ressaltar a importância que tais relações têm na vida cotidiana dos Timbira, havendo inclusive indícios de que as relações de amizade formal podem ter influência sobre 


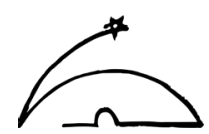

escolhas matrimoniais (GIRALDIN, 2011; COELHO DE SOUZA, 2012; PAULINO, 2016; e também LEA, 1995 para o caso dos Mẽbêngôkre)

De acordo com a literatura que venho citando sobre os povos Timbira, é somente na classificação dos primos cruzados e de seus descendentes que as terminologias desses povos seriam divergentes. Na figura III, temos um esquema que representa as possibilidades de aplicação de termos de parentesco para essas posições entre os Kraho e Canela, conforme descrita por Ladeira (1982). Vale notar que os termos keti (3) e tyj (4) tendem a se transformar nas formas ketre e tyre, já mencionadas anteriormente, quando aplicados a pessoas de geração igual ou inferior a ego.

Melatti, em sua descrição da terminologia Kraho, inicialmente apresenta essas posições como definidas segundo uma regra de obliquidade de tipo Crow (termos à esquerda na figura III). No entanto, o próprio autor nota que “(...) uma feição Omaha surge apenas em casos concretos de transmissão de nome pela irmã do pai (...)” (MELATTI, 1973: 23). Tal feição (representada pelos termos à direita na figura III), pode ser facilmente explicada como fruto da identificação entre pessoas de mesmo nome citada anteriormente, já que consiste em ego feminino chamar seus primos(as) cruzados(as) patrilaterais como chama seus próprios filhos(as), identificando-se com sua tia paterna que pode lhe transmitir seus nomes; ao mesmo tempo em que chama sua prima cruzada matrilateral como chama sua mãe, pois a primeira poderia receber nomes da segunda.

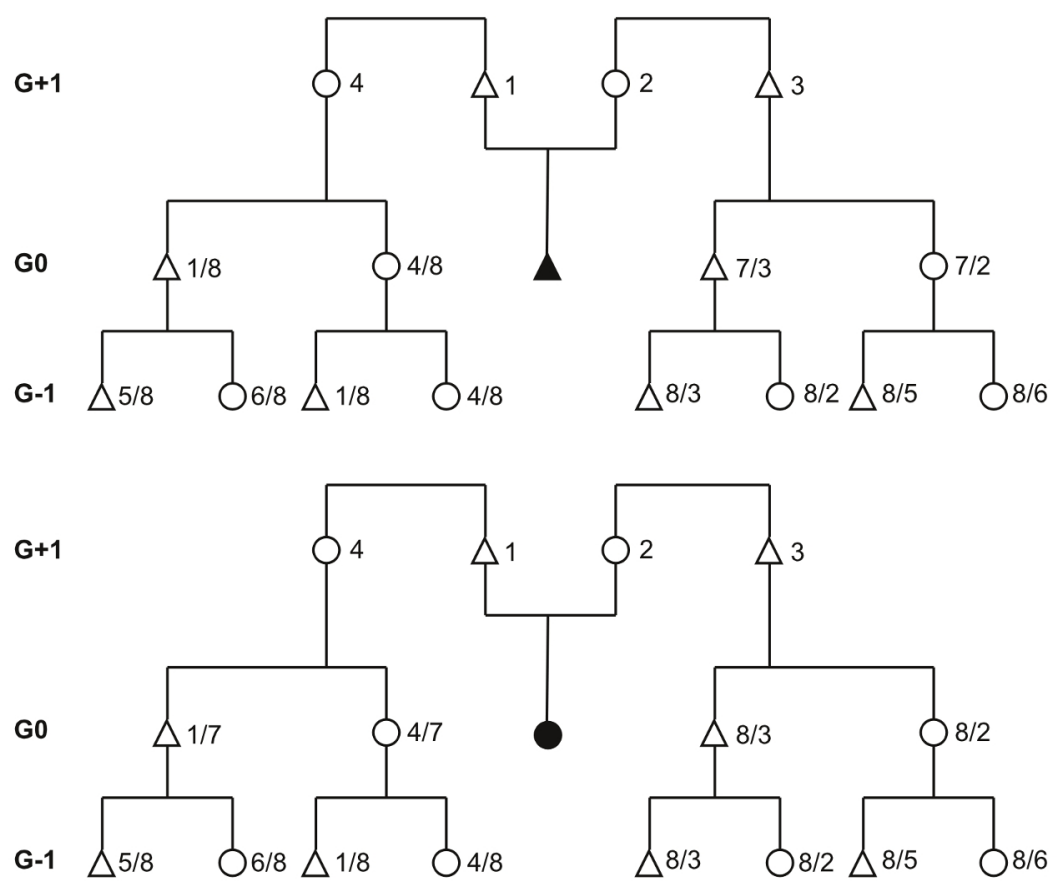

Figura III. As possibilidades de classificação dos primos cruzados e seus filhos(as) segundo padrões Crow/ Omaha para ego masculino e feminino. As classificações em $\mathrm{G}^{+1}$ não variam.

Fonte: PAULINO, 2016; MELATTI 1973; LADEIRA 1982. 
No mesmo sentido de Melatti, Ladeira (1982), argumentando que a transmissão de nomes é uma das bases que organiza o sistema de parentesco Timbira, mostra como, dependendo das diferentes possibilidades de identificação entre pessoas por via da transmissão de nomes, a terminologia Timbira possibilita, para pessoas de ambos os sexos, tanto classificações de primos cruzados que seguem o padrão Crow quanto outras que seguem o padrão Omaha. Como consequência lógica, os descendentes dos primos cruzados também podem ser classificados segundo padrões Crow e/ou Omaha. Essa ambiguidade classificatória permite equacionar terminologicamente os primos cruzados a parentes próximos e paralelos ou equacioná-los a parentes cruzados de gerações diferentes.

Os dados ${ }^{5}$ que obtive durante minha pesquisa, embora em pequena quantidade, parecem indicar que, entre os Kraho, a feição Crow é de fato predominante, embora outras classificações para os primos cruzados sejam perfeitamente possíveis (havendo, inclusive, casos de casamentos entre eles), o que pode ser um sinal de uma maior distância relativa dos parentes que ocupam essas posições com relação às outras posições até aqui apresentadas.

O reconhecimento da existência de possibilidades Crow e/ou Omaha assemelha essas terminologias à terminologia Apinajé que, conforme descrita por DaMatta, também combina padrões Crow e Omaha. Porém, esse autor descreve ainda outra possibilidade de classificação e combinação dos padrões de obliquidade Crow-Omaha realizada pelos Timbira (termos à esquerda na figura IV), em que para os parentes de um lado se utiliza um padrão Crow e para os parentes de outro lado, um padrão Omaha. Ao descrever essa possibilidade, DaMatta se foca na perspectiva de um ego qualquer, já que o uso sistemático dessa possibilidade por todas as pessoas seria inconsistente com o uso recíproco de termos tais como keti (3) / itamxwy (8), tyj (4) / itamxwy (8), inxũ (1) / ikra (7) e inxe (2) / ikra (7) ${ }^{6}$. Assim, como o próprio autor reconhece (DAMATTA, 1976), essa possibilidade classificatória pressupõe a existência da possibilidade recíproca (termos à direita na figura IV), que no entanto não nos é apresentada por ele em forma de diagrama. Embora a utilização sistemática dessas possibilidades combinatórias não seja viável devido à inconsistência entre termos recíprocos, é perfeitamente cabível que em casos específicos encontremos pessoas que escolheram utilizá-las para classificar suas relações com seus primos cruzados, já que se trata apenas de uma outra combinação de possibilidades já abertas pelos padrões Crow e Omaha.

$5 \quad$ Ver PAULINO, 2016, anexo II.

6 Um exemplo a título de ilustração: se ego masculino chamar seu alter MBS de keti (3), esse alter por sua vez deveria chamá-lo de itamxwy (8), termo recíproco. Entretanto, se seguirmos a mesma lógica classificatória, alter chamaria ego de inxũ (1), já que ego é FZS de alter. O mesmo acontece em todos os casos. 


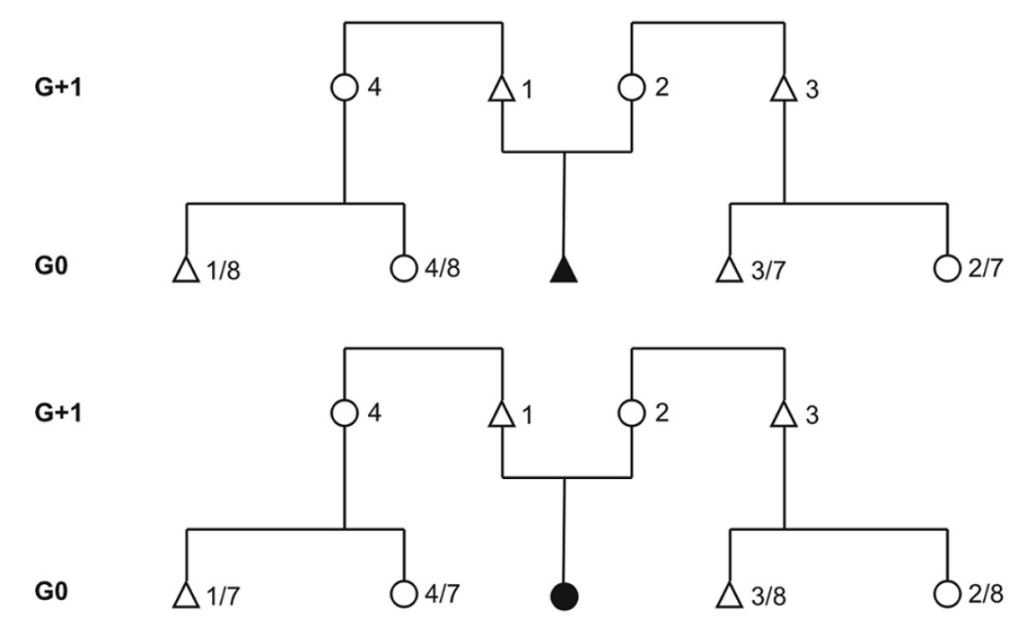

Figura IV. A combinação descrita por DaMatta em que os primos cruzados de ambos os lados são terminologicamente igualados $\mathrm{a} \mathrm{G}^{+2}$ (à esquerda); e outra combinação possível em que os primos cruzados de ambos os lados são terminologicamente igualados a gerações abaixo de ego (à direita). Fonte: PAULINO, 2016;

DAMATTA, 1976.

A aplicação na prática das possibilidades descritas é certamente mais complexa do que o modelo, já que qualquer pessoa pode utilizar - conforme o contexto e seu interesse pessoal - um ou outro padrão para classificar cada um de seus primos cruzados e seus descendentes, podendo também utilizar outros critérios que não o genealógico para a classificação (como a partilha de substância, homonímia, ou amizade formal, por exemplo). O mesmo vale também para as relações descritas nas figuras anteriores; ao tratar de casos empíricos, nunca podemos esquecer que as relações (de parentesco ou não) são constantemente atualizadas pelas ações das pessoas. Portanto, embora esteja trabalhando com descrições que partem de relações de filiação e casamento, subscrevo o entendimento de que essas mesmas relações de parentesco também podem ser constituídas de outras formas, entendimento esse que parece ser um ponto pacífico nos atuais estudos de parentesco (SAHLINS, 2013).

Concluindo a descrição do modelo, penso que temos base para falar de uma terminologia de parentesco Timbira que é fundamentalmente a mesma para todos os povos agrupados sob essa alcunha, e cujas variações (sejam elas entre povos ou interiores a um mesmo povo) estariam todas dentro do escopo abrangido pelas possibilidades de equações Crow e/ou Omaha, denotando assim a existência de um sistema de parentesco que ultrapassa as fronteiras definidas por etnônimos; fato confirmado também pela existência de casamentos e mobilidade de pessoas entre os diferentes povos e aldeias. Embora não tenha citado em momento algum dados sobre os Gavião ou Krĩkati, os comentários de DaMatta e Laraia sobre a organização social e o sistema de parentesco dos primeiros, e as referências dos diversos autores citados ao trabalho de Lave sobre os segundos, levam a crer que podemos sem risco incluí-los no modelo (Cf. DAMATTA; LARAIA, 1979; LAVE, 1967 apud DAMATTA, 1976). De fato, como já mencionado, o modelo proposto 
poderia até mesmo englobar as terminologias de outros povos jê do norte como, por exemplo, os Mebêngokrê, cuja terminologia foi descrita por Lea (2012) com equações de obliquidade de tipo Omaha.

Passo agora a uma breve exposição sobre alguns costumes Timbira para na sequência argumentar sobre como a terminologia pode influenciar as escolhas e trocas matrimoniais entre esses povos.

Embora as sociedades Timbira tenham uma profusão de metades e grupos ligados à vida cerimonial, não há indícios de relação direta entre esses entes e as trocas matrimoniais, ou da existência de qualquer tipo de regra positiva de casamento. Melatti, ao tratar da organização da vida doméstica Kraho, cunhou o conceito de segmento residencial como um conjunto de casas próximas espacialmente em que as mulheres estão relacionadas entre si por linhas femininas, devido à regra de residência uxorilocal. Os segmentos residenciais não são nomeados nem claramente definidos pelos Kraho, muito embora eles reconheçam que pessoas que moram em casas próximas são em geral relacionadas de alguma forma. No entanto, esses segmentos possuem uma característica marcante: são exogâmicos. Cumpre notar que tal característica - que também não é formulada em termos de segmento residencial pelos Kraho - está justamente ligada a esse relacionamento reconhecido entre pessoas que moram próximas umas das outras (MELATTI, 1973).

Ladeira concorda com Melatti ao notar que os segmentos residenciais tendem, com poucas exceções, à exogamia, o que equivale dizer que parentes matrilaterais próximos (que pela residência uxorilocal moram no mesmo segmento residencial) não casam uns com os outros (LADEIRA, 1982). Essa autora indica ainda duas tendências opostas que orientam as escolhas matrimoniais entre os Timbira. Por um lado, homens que se tratam como irmãos tenderiam a buscar mulheres numa mesma casa como forma de reduzir a tensão da convivência entre homens oriundos de diferentes segmentos que ocorre com a uxorilocalidade, ou seja, com o costume dos homens irem viver junto à família de suas esposas. Por outro lado, aparece a tendência de mães buscarem casar seus filhos em diferentes segmentos, o que evidencia a importância política dos casamentos para o estabelecimento de alianças entre as parentelas (Ibid).

Porém, a maior contribuição de Ladeira para o entendimento do regime de trocas entre os Timbira está em sua análise de uma prática relacionada à transmissão onomástica que os Canela chamam de ituare $^{7}$, que permite a ela demonstrar como "(...) a implicação básica deste sistema de transmissão de nomes é a possibilidade da troca de nomes e dos casamentos 'caminharem juntos"” (Ibid: 55). A autora descreve em detalhes a prática do ituare, que consiste basicamente na troca de nomes entre crianças que formem um par itõ (5) / itoĩ (6) para que, quando se casem,

7 Os Kraho têm o mesmo costume, chamado entre eles de ipantu, mesma palavra utilizada por um ego qualquer para se referir àquele(a) a quem transmitiu nome (ver termo 20 da descrição terminológica) (LADEIRA, 1982). 


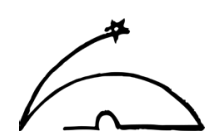

transmitam o nome um do outro para seus primogênitos de sexo oposto. A prática do ituare implica no uso de uma série de termos especiais entre esse par de irmãos, os parentes próximos deles, entre eles e seus respectivos cônjuges e também em referência a eles após o nascimento de seus primogênitos (Ibid). Como a prática do ituare é realizada durante a infância, um homem e uma mulher ao se casarem não estão apenas recebendo um cônjuge, mas também, junto com ele, um nome que será transmitido ao seu primogênito de mesmo sexo. Troca de nomes e troca de cônjuges são duas facetas da relação de aliança entre os Timbira.

O modelo da terminologia Timbira aqui apresentado também nos permite fazer mais algumas considerações sobre como - ainda que não haja entre os Timbira regra positiva de casamento - a terminologia de parentesco pode influenciar as escolhas matrimoniais nessas sociedades. Como vimos, há na terminologia Timbira ao menos duas formas de identificação entre pessoas, ou, em outras palavras, há duas formas de pessoas diferentes aplicarem os mesmos termos de parentesco a terceiros: através do princípio de unidade do grupo de irmãos de mesmo sexo e através da transmissão de nomes. Se observarmos a terminologia de afins, veremos já alguns indícios do primeiro princípio em operação, como nas equações $\mathrm{H}=\mathrm{HB}$ e $\mathrm{W}=\mathrm{WZ}$. Entretanto, nessas duas equações, ego é uma pessoa já casada, não sendo, portanto, possível depreender nada sobre suas escolhas matrimoniais a partir daí. Porém, se considerarmos que os itõ (5) ou itoĩ (6) de mesmo sexo de ego podem aplicar a terminologia a qualquer pessoa como se fossem ego, temos então as equações $\mathrm{BWZ}=\mathrm{W}$ e $\mathrm{ZHB}=\mathrm{H}$ que podem ser aplicadas por pessoas não casadas em relação a outras pessoas não casadas, classificando-as assim como cônjuges potenciais (ou parceiros sexuais em potencial). Se, além da possibilidade de identificação entre irmãos(ãs) de mesmo sexo, considerarmos também a possibilidade de identificação através da homonímia (transmissão de nomes), temos o quadro de permutações abaixo com as possibilidades de relações em que duas pessoas não casadas podem se classificar mutuamente como cônjuges. A partir dessas relações é possível, como fiz em outra oportunidade (PAULINO, 2016), analisar as redes empíricas de parentesco e transmissão de nomes para verificar a frequência com que de fato tais relações resultam em casamentos.

\begin{tabular}{|c|c|c|}
\hline Identificaçōes: & $\begin{array}{l}\text { De uma mulher com sua } \\
\text { homônima }\end{array}$ & $\begin{array}{l}\text { De uma mulher com sua } \\
\text { irmã - itoĩ (6) }\end{array}$ \\
\hline $\begin{array}{l}\text { De um homem com } \\
\text { seu homônimo }\end{array}$ & $\begin{array}{l}\text { Homem pode classificar } \\
\text { como iprõ (10) uma mulher } \\
\text { que tem o mesmo nome que } \\
\text { a esposa de um homem que } \\
\text { tem o mesmo nome que si }\end{array}$ & $\begin{array}{l}\text { Homem pode classificar como } \\
\text { iprõ (10) uma mulher que é } \\
\text { irmã da esposa de um homem } \\
\text { que tem o mesmo nome que si }\end{array}$ \\
\hline $\begin{array}{l}\text { De um homem com } \\
\text { seu irmão - itõ (5) }\end{array}$ & $\begin{array}{l}\text { Homem pode classificar } \\
\text { como iprõ (10) uma mulher } \\
\text { que tem o mesmo nome que } \\
\text { a esposa de seu irmão }\end{array}$ & $\begin{array}{l}\text { Homem pode classificar como } \\
\text { iprõ (10) uma mulher que é } \\
\text { irmã da esposa de seu irmão }\end{array}$ \\
\hline
\end{tabular}

Tabela I. Quadro de permutações de possibilidades de identificação baseadas nos princípios de unidade do grupo de irmãos de mesmo sexo e identificação entre pessoas homônimas. Utilizo ego masculino, mas é possível construir o mesmo quadro a partir de ego feminino. Os termos "irmão" e "irmã” representam sempre os termos itõ (5) e itõ (6), 
incluindo assim tanto irmãos(ãs) quanto primos(as) paralelos(as); de fato, é mais comum que se tratem de primos(as) paralelos(as) que de irmãos(ãs), ainda que terminologicamente eles não se distingam. Fonte: PAULINO, 2016.

Assim, me parece claro como a descrição da terminologia Timbira nos permite entender melhor o modo de operação desse saber e como ele está intrinsecamente relacionado com o sistema de atitudes e as trocas matrimoniais e onomásticas nessas sociedades. Essa relação não é de causalidade em qualquer dos sentidos, mas sim de integração dinâmica e influência mútua, conforme já proposto por Lévi-Strauss ([1945] 2003).

Por fim, buscando situar a terminologia Timbira no contexto mais amplo das terras baixas sul-americanas, lembremos que Viveiros de Castro (1996) propõe um modelo geral para pensar os sistemas de parentesco das regiões amazônicas e centro-brasileiras em que a lei estrutural é a oposição não neutralizável entre consanguíneos e afins em $\mathrm{G}^{+1}$; oposição essa que seria resultado de uma troca simétrica ocorrida nessa geração e que orientaria as trocas subsequentes. Já a posição dos parentes cruzados em $\mathrm{G}^{0}$ seria uma "casa vazia" preenchida de formas diferentes por cada sociedade em cada caso (VIVEIROS DE CASTRO, 1996). As trocas onomásticas entre os Kraho e Canela se prestam a essa noção de troca simétrica em $\mathrm{G}^{+1}$, já que a troca de nomes através do ituare é sempre uma troca simétrica e poderia, do ponto de vista de ego, ter acontecido entre inxũ (1) / tyj (4) e/ou entre inxe (2) / keti (3). Assim, para os Timbira, há uma oposição entre os parentes paralelos e cruzados em $\mathrm{G}^{+1}$ que não pode ser neutralizada, enquanto em $\mathrm{G}^{0}$ há diferentes possibilidades de classificação abertas para os parentes cruzados dentro dos padrões Crow-Omaha.

O mesmo autor levanta também a hipótese de que toda e qualquer regra de cruzamento é compatível com algum regime de trocas matrimoniais; o cruzamento é para ele uma noção derivada de estruturas de aliança que, portanto, sempre deve ter implicações matrimoniais (o que não significa necessariamente existência de regras prescritivas de casamento) (VIVEIROS DE CASTRO, 1998). De fato, é possível demonstrar, como feito por Trautmann (2012), que os sistemas de tipo Dravidiano, Iroquês e Crow-Omaha (todos presentes de alguma forma entre os povos das terras baixas) estão ligados por uma série de transformações estruturais. Para Trautmann, o que a obliquidade faz é dividir os parentes cruzados (que a princípio formam um grupo único, como nos sistemas Dravidianos ou Iroqueses) em dois grupos que serão tratados de formas distintas. No caso Timbira, como visto, as regras de cruzamento e obliquidade estão diretamente ligadas à transmissão de nomes, que por sua vez proporciona identificações entre pessoas que podem levar a implicações matrimoniais; assim, podemos dizer que o cruzamento e a obliquidade dizem respeito não somente ao regime de trocas matrimoniais como propôs Viveiros de Castro, mas também de trocas onomásticas, ambos parte do regime mais amplo de reciprocidade dessas sociedades. 


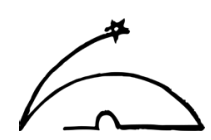

\section{Referências Bibiográficas}

AZANHA, Gilberto. Forma Timbira: estrutura e resistência. Dissertação (Mestrado em Antropologia Social) PPGAS, USP, São Paulo, SP, 1984.

CARNEIRO DA CUNHA, Manuela. De amigos formais e pessoa; de companheiros, espelhos e identidades. In: . Antropologia do Brasil: mito, história, etnicidade. São Paulo: Brasiliense, Editora da Universidade de São Paulo, [1979]1986. p. 53-62.

COELHO DE SOUZA, Marcela. Parentes de sangue: incesto, substância e relação no pensamento Timbira. Mana, v. 10, n. 1, p. 25-60, 2004.

The Making and Unmaking of 'Crow-Omaha' Kinship in Central Brazil(ian Ethnology). In: TRAUTMANN, Thomas; WHITELEY, Peter (Eds.). Crow-Omaha: new light on a classic problem of kinship analysis. Tucson: The University of Arizona Press, 2012. p. 205-222.

DAMATTA, Roberto. Um mundo dividido: estrutura social dos índios Apinayé. Petrópolis: Vozes, 1976.

DAMATTA, Roberto; LARAIA, Roque. Índios e castanheiros: a empresa extrativa e os índios no médio Tocantins. Rio de Janeiro: Paz e Terra, [1978]1979.

GIRALDIN, Odair. Creating Affinity: Formal Friendship and Matrimonial Alliances Among the Jê People and the Apinaje case. Vibrant - Virtual Brazilian Anthropology, v. 8-2, p. 403-426, 2011.

LADEIRA, Maria Elisa. A troca de nomes e a troca de cônjuges - uma contribuição ao estudo do parentesco Timbira. Dissertação (Mestrado em Antropologia Social) - PPGAS, USP, São Paulo, SP, 1982.

LAVE, Jean Elizabeth Carter. 1967. Social taxonomy among the Krikati (Ge) of Central Brazil. Tese (Doutorado em Antropologia) - Harvard University, Cambridge, EUA, 1967.

LEA, Vanessa. Casa-se do outro lado: Um modelo simulado da aliança Mebengokre (jê). In: VIVEIROS DE CASTRO, Eduardo (Ed.). Antropologia do Parentesco: Estudos Ameríndios. Rio de Janeiro, Editora UFRJ, 1995. p. $321-359$. . Riquezas Intangíveis de Pessoas Partíveis. São Paulo: Edusp, Fapesp, 2012.

LÉVI-STRAUSS, Claude. A Análise Estrutural em linguística e Antropologia. In: . Antropologia Estrutural.

Rio de Janeiro: Tempo Brasileiro, [1945]2003. 
LOUNSBURY, Floyd G. A Formal Account of the Crow - and Omaha - Type Kinship Terminologies. In: GOODENOUGH, Ward H. (Ed.). Explorations in Cultural Anthropology: Essays in Honor of George Peter Murdock. New York: McGraw-Hill, 1964. p. 351-393.

MELATTI, Julio Cezar. O Sistema Social Craô. Tese (Doutorado em Antropologia Social) - PPGAS, USP, São Paulo, SP, 1970.

. O Sistema de Parentesco dos Índios Krahô. Série Antropologia, Brasília, v. 3. 1973. Disponível em: http:// www.juliomelatti.pro.br/artigos/a-parentescocrao.pdf. Acesso em: 07 mai. 2019.

MURDOCK, George Peter. Social Structure. New York: Macmillan, 1949.

PAULINO, Carlos. A rede mehĩ: em busca de estruturas de troca e parentesco Kraho. Dissertação (Mestrado em Antropologia Social) - PPGAS, USP, São Paulo, SP, 2016.

SAHLINS, Marshall. What kinship is - and is not. Chicago: The University of Chicago Press, 2013.

SILVA, Marcio. O grande jogo do casamento: um desafio antropológico e computacional em área de fronteira. Revista De Antropologia, v. 60, n. 2, p. 356-382, 2017.

TRAUTMANN, Thomas. Crossness and Crow-Omaha. In: TRAUTMANN, Thomas; WHITELEY, Peter (Eds.). Crow-Omaha: new light on a classic problem of kinship analysis. Tucson: The University of Arizona Press, 2012. p. 31-50.

VIVEIROS DE CASTRO, Eduardo. Ambos os três: sobre algumas distinções tipológicas e seu significado estrutural na teoria do parentesco. Anuário Antropológico/95. Rio de Janeiro: Tempo Brasileiro, 1996. p. 9-91.

. Dravidian and Related Kinship Systems. In: GODELIER, M.; TRAUTMANN, T.; TJON SIE FAT, F. (Eds.). Transformations of Kinship. Washington and London: Smithsonian Institution Press, 1998. p. 332-385.

. Atualização e contra-efetuação do virtual: o processo do parentesco. In: . A inconstância da alma selvagem e outros ensaios de antropologia. São Paulo: Cosac \& Naify, 2002. p. 401-456. 